Article

\title{
Structural and Thermal Characterization of Novel Organosolv Lignins from Wood and Herbaceous Sources
}

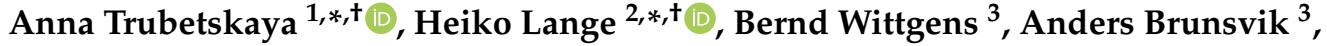 \\ Claudia Crestini ${ }^{4}{ }^{\mathbb{D}}$, Ulrika Rova ${ }^{5}$, , Paul Christakopoulos ${ }^{5}$, J. J. Leahy ${ }^{1}$ \\ and Leonidas Matsakas ${ }^{5, *,+(\mathbb{D})}$ \\ 1 Bernal Center, University of Limerick, V94 T9PX Castletroy, Ireland; J.J.Leahy@ul.ie \\ 2 Department of Pharmacy, University of Naples 'Federico II', 80131 Naples, Italy \\ 3 SINTEF Industry, Richard Birkelands vei 2B, 7034 Trondheim, Norway; Bernd.Wittgens@sintef.no (B.W.); \\ Anders.Brunsvik@sintef.no (A.B.) \\ 4 Department of Molecular Science and Nanosystems, University of Venice Ca' Foscari, Via Torino 155, \\ 30170 Venice Mestre, Italy; claudia.crestini@unive.it \\ 5 Biochemical Process Engineering, Division of Chemical Engineering, Department of Civil, \\ Environmental and Natural Resources Engineering, Luleå University of Technology, 97187 Luleå, Sweden; \\ Ulrika.Rova@ltu.se (U.R.); paul.christakopoulos@ltu.se (P.C.) \\ * Correspondence: atrubetskaya@gmx.de (A.T.); heiko.lange@unina.it (H.L.); leonidas.matsakas@ltu.se (L.M.) \\ + These authors contributed equally to this work.
}

Received: 26 June 2020; Accepted: 13 July 2020; Published: 17 July 2020

check for updates

\begin{abstract}
This study demonstrates the effects of structural variations of lignins isolated via an organosolv process from different woody and herbaceous feedstocks on their thermal stability profiles. The organosolv lignins were first analysed for impurities, and structural features were determined using the default set of gel permeation chromatography, FT-IR spectroscopy, quantitative ${ }^{31} \mathrm{P}$ NMR spectroscopy and semi-quantitative ${ }^{1} \mathrm{H}_{-}-{ }^{13} \mathrm{C}$ HSQC analysis. Pyrolysis-, $\mathrm{O}_{2}$ - and $\mathrm{CO}_{2}$-reactivity of the organosolv lignins were investigated by thermogravimetric analysis (TGA), and volatile formation in various heating cycles was mapped by head-space GC-MS analysis. Revealed reactivities were correlated to the presence of identified impurities and structural features typical for the organosolv lignins. Data suggest that thermogravimetric analysis can eventually be used to delineate a lignin character when basic information regarding its isolation method is available.
\end{abstract}

Keywords: lignin; organosolv fractionation; TGA; ${ }^{31} \mathrm{P}$ NMR; HSQC; heat treatment

\section{Introduction}

Lignocellulosic feedstocks hold a potential for large-scale production of second-generation biofuels leading to a decarbonization of the energy sector [1]. The fractionation of biomass into cellulose, hemicellulose, lignin and extractives provides valuable feedstocks for the energy sector and the chemical industries [2]. While cellulose and hemicellulose represent structurally regular polymers, extractives and lignin represent a more difficult starting material for valorisation. In case of lignin, not only the (presumably) uncontrolled biosynthesis leading to random polymer linkages, but also the biomass-dependent distribution of monomeric building blocks mark challenging aspects. The relative abundance of these monomers within a lignin polymer leads to the common differentiation between lignins isolated from softwood, hardwood or herbaceous biomass [3]. The polymeric lignin structure present in the plants is more resistant to most forms of biological attacks, sunlight and temperature changes compared to polysaccharides, contributing thus to the industrial challenges faced in lignin 
valorisation [4]. Once separated from the other biopolymers, lignin has nevertheless been utilized as a primary feedstock for composites, PU-based foams, films, paints, and plastics [5]. From a different technical point of view, lignin rich feedstocks present challenges for gas cleaning units of gasification reactors as high concentration of lignin may increase soot yields in addition to increasing formation of PAH precursors [6]. Thus, removal of lignin from biomass is important to prevent outlet blockages and to ensure steady syngas production increasing overall efficiency of the gasification process.

When it comes to the production of biofuels from low cost lignocellulosic biomass, such as agricultural or forestry residues, a typical process consists of biomass pretreatment, enzymatic saccharification of the carbohydrates and microbial conversion of the sugars to biofuels [7]. The main aim of pretreatment is to efficiently remove hemicellulose and lignin from cellulose and increase the susceptibility of cellulose to enzymatic hydrolysis [8]. Removal of lignin from cellulose is particularly important as lignin has a negative influence on enzymatic saccharification due to the irreversible adsorption of cellulolytic enzymes onto lignin and their inhibition from soluble lignin-derived molecules [9]. Hydrothermal pretreatment is one of the most common methods to pretreat lignocellulosic biomass, which effectively degrades hemicelluloses, even without chemicals, increases the biomass porosity, thus enhancing the enzymatic hydrolysis of the pre-treated biomass [10]. The common challenge of hydrothermal pretreatment is that lignin cannot be directly removed and hence partly rearranges on the surface of the lignocellulosic biomass, causing an inhibitory effect on the saccharification process [11,12]. Organosolv pretreatment is known as an effective method to fractionate biomass into cellulose, hemicellulose and lignin streams by using aqueous-organic solvent mixtures, with high solvent concentration (30-70\%) at temperatures of $100-22{ }^{\circ} \mathrm{C}$, with or without the addition of catalysts $[13,14]$. One of the main benefits of organosolv pretreatment is the isolation of high-quality lignin and cellulose fractions $[15,16]$. Another two advantages of the organosolv process are related to the relative easy recovery and re-use of the commonly used organic solvents (such as ethanol or acetone) and improved mass transfer and dissolution of lignin in the presence of an organic solvent [17-19]. Previous research showed that organosolv pulps have bleachability and viscosity retention which are comparable to those of cellulose soda and kraft pulps [20]. Most studies [21-23] investigated the effect of feedstock on the chemical properties of lignocellulosic fractions from the organosolv wood pre-treatment, whereas the chemical properties and reactivity of lignocellulosic fractions after organosolv treatment of herbaceous biomass are rarely studied in the literature.

In a previous work [7], the efficiency of organosolv pretreatment on wood at different operating conditions such as type of solvent, lack or presence of homogeneous catalyst, and type of homogeneous acid catalyst was investigated. The aim of the present study was to evaluate the properties of lignins isolated from various feedstocks via the previously described novel organosolv processes [7,9]. Structural and physicochemical characteristics of five different lignins were elucidated using established analysis methods: Gel permeation chromatography for molecular mass features, quantitative ${ }^{31} \mathrm{P}$ NMR and comparative two-dimensional ${ }^{1} \mathrm{H}-{ }^{13} \mathrm{C}$ HSQC analyses for more detailed structural aspects. Another aim of this work was to investigate to which extent the structural differences would be reflected in gas chromatographic analysis for determining initially present volatiles and inducible volatile contents, as well as in thermogravimetric analysis for delineating polymer characteristics and lignin reactivity in different atmospheres [12]. Structural information obtained by the various methods was correlated to findings in head-space GC-MS and thermal analyses. The presented analyses offer a solid base on which a specific lignin could be chosen for a value-added application.

\section{Materials and Methods}

\subsection{Raw Materials}

In the present study, both wood (pine sawdust and spruce bark) and herbaceous biomass (cotton stalks and sweet sorghum bagasse) were used as raw materials. Pine sawdust and spruce bark were 
obtained from mills from Northern Sweden, cotton stalks were obtained from fields in Thessaly (Greece), and sweet sorghum (Keller cultivar) was obtained from fields in the Kopaida plain (Central Greece). The materials, apart from sweet sorghum, were immediately air-dried upon receive, milled to particle size $<$ $1 \mathrm{~mm}$ and stored at room temperature. For the preparation of sweet sorghum bagasse, the sugars were extracted from the sweet sorghum stalks as previously described [24] and bagasse was dried, milled and stored at room temperature. Finally, spruce bark was treated in hot-water extraction $\left(75^{\circ} \mathrm{C}\right.$ for $2 \mathrm{~h}$ ) with the addition of sodium bisulfite $\left(2 \% \mathrm{w} / \mathrm{w}_{\text {biomass }}\right)$ and sodium carbonate $\left(0.5 \% \mathrm{w} / \mathrm{w}_{\text {biomass }}\right)$ to remove the tannin and other water soluble extractives [25]. After hot-water extraction, the tannin-extracted bark solids were removed from the process by vacuum filtration, washed with water and air dried.

\subsection{Organosolv Fractionation}

Pine sawdust and cotton stalks were treated in a hybrid organosolv: steam explosion reactor which was previously described [9], whereas sweet sorghum bagasse and tannin-extracted spruce bark were treated in an autoclave organosolv reactor, as reported previously [7]. The organosolv treatment conditions for the different feedstock were as follows: pine sawdust was treated at $190{ }^{\circ} \mathrm{C}$ for $60 \mathrm{~min}$ in a $60 \% \mathrm{v} / \mathrm{v}$ ethanol solution with the addition of $1 \% \mathrm{w} / \mathrm{w}_{\text {biomass }}$ sulfuric acid; cotton stalks were treated at $200^{\circ}$ for $45 \mathrm{~min}$ in a $50 \% \mathrm{v} / \mathrm{v}$ ethanol solution with the addition of $1 \% \mathrm{w} / \mathrm{w}_{\text {biomass }}$ sulfuric acid; sweet sorghum bagasse was treated at $180{ }^{\circ} \mathrm{C}$ for $30 \mathrm{~min}$ in a $60 \% \mathrm{v} / \mathrm{v}$ ethanol solution; tannin-extracted bark was treated at $180{ }^{\circ} \mathrm{C}$ for $1 \mathrm{~h}$ with $60 \% v / v$ ethanol content, with and without the use of $1 \%$ $\mathrm{w} / \mathrm{w}_{\text {biomass }}$ sulfuric acid. At the end of the organosolv treatment, the pretreated solids were separated from the liquor by vacuum filtration. Lignin was recovered from the liquor by centrifugation after ethanol removal in a rotary evaporator. Finally, lignin was air-dried and stored at room temperature. In the manuscript, the abbreviations of lignin fractionated from pine sawdust (PL), cotton stalks (CL), sweet sorghum bagasse (SSL), spruce bark with (SBAL) and without acid addition (SBNL) were used.

\subsection{Lignin Characterization}

\subsubsection{Elemental Analysis}

The elemental analysis was performed on two instruments of the same model (Eurovector, model EA3000). Acetanilide was used as a reference standard. The ash content was determined using a standard ash test at $550{ }^{\circ} \mathrm{C}$, according to the procedure described in DIN EN 14775 .

\subsubsection{Headspace Gas Chromatography-Mass Spectroscopy}

Approximately $20 \mathrm{mg}$ of a lignin sample was accurately weighed and directly sealed into a $20 \mathrm{~mL}$ headspace vial. Headspace gas chromatography-mass spectroscopy (HSGC-MS) analysis was performed using an Agilent 7694E Headspace sampler (Agilent Technologies, Santa Clara, CA, US), connected to an Agilent 7890B series gas chromatograph coupled with an Agilent 5977A series mass spectrometer and equipped with a HP-5MS Agilent column $(0.25 \mathrm{~mm} \times 30 \mathrm{~m} \times 0.25 \mu \mathrm{m})$. The headspace operating conditions were as follows: The equilibration time was $20 \mathrm{~min}$; the headspace oven, loop, and transfer line temperatures were 110,180 and $270{ }^{\circ} \mathrm{C}$; 130, 200 and $280^{\circ} \mathrm{C}$; and 130, 200 and $280^{\circ} \mathrm{C}$ respectively; the shaking time was $2 \mathrm{~min}$ at low intensity; the injecting time was $2 \mathrm{~min}$. GC operating conditions were as follows: the carrier gas (helium) was set at a flow rate of $1.0 \mathrm{~mL} \mathrm{~min}^{-1}$ with the split ratio was 5:1; the column temperature program was initially set at $50{ }^{\circ} \mathrm{C}$ for $1 \mathrm{~min}$, and was gradually increased to $100{ }^{\circ} \mathrm{C}$ at $3{ }^{\circ} \mathrm{C} \mathrm{min}{ }^{-1}$, then kept for $3 \mathrm{~min}$ before being gradually increased to 110,180 , or $270{ }^{\circ} \mathrm{C}$ at $10^{\circ} \mathrm{C} \mathrm{min}^{-1}$; for MS detection, an electron ionization (EI) system was used with the ionization energy at $70 \mathrm{eV}$; the temperature of the ion source and the quadrupole temperature was 230 and $150{ }^{\circ} \mathrm{C}$, respectively; the mass range was 50-550 amu in the full-scan acquisition mode with $3 \mathrm{~min}$ of solvent delay. The HSGC-MS collected data were processed by MassHunter Qualitative Analysis B.06.00 for the peak deconvolution. 
The mass spectra with the well-resolved overlapping peaks were imported into the mass spectra library software NIST MS Search 2.3 [26].

\subsubsection{Molecular Weight Determination of Lignin}

Lignin molecular weight and molecular weight distribution were determined by gel permeation chromatography (GPC) as described previously [27] after being acetobrominated according to the protocol proposed by Asikkala et al. [28]. More specifically, approximately $5 \mathrm{mg}$ of lignin was initially reacted in a $1 \mathrm{~mL}$ solution of 9:1 $v / v$ of glacial acetic acid/acetyl bromide (Sigma Aldrich, St. Louis, MO, USA) for $2 \mathrm{~h}$, followed by removal of the solvent in a rotary evaporator. The sample was then dissolved in THF (tetrahydrofuran; VWR Chemicals, Radnor, PA, USA), followed by solvent removal. This process was done twice, to ensure that glacial acetic acid and acetyl bromide were properly removed. Finally, the sample was dissolved in $1 \mathrm{~mL}$ of THF and used for the determination of the molecular weight. GPC analysis was done in an HPLC apparatus equipped with a UV detector (PerkinElmer Flexar, Watham, MA, USA) and a Styragel HR 4E (Waters; Miford, MA, USA) chromatographic column. THF was used as mobile phase at $0.6 \mathrm{~mL} \mathrm{~min}^{-1}$ flow rate, and the column was kept at $40{ }^{\circ} \mathrm{C}$. The $\mathrm{UV}$ detector was set at $280 \mathrm{~nm}$. The calibration curves were prepared by using polystyrene standards (Sigma Aldrich). Molecular masses calculated based on the calibration were rounded to the full hundreds.

\subsubsection{FTIR Spectroscopy}

The lignin samples were analyzed by a Cary 630 FTIR spectrometer (Agilent Technologies, Santa Clara, CA, USA). All absorption spectra were obtained in the $4000-600 \mathrm{~cm}^{-1}$ range by 100 scans at $4 \mathrm{~cm}^{-1}$ resolution. For background, 200 scans were acquired. Good contact between sample and ATR-crystal surface was ensured before all measurements. All samples were measured in triplicate.

\subsubsection{Quantitative ${ }^{31} \mathrm{P}$ NMR Analysis}

In general, a procedure similar to the one originally published and previously applied was used [29]. Approximately $30 \mathrm{mg}$ of the lignin were accurately weighed for analysis in a volumetric flask and suspended in $400 \mu \mathrm{L}$ of a solvent mixture of pyridine and deuterated chloroform $\left(\mathrm{dCDCl}_{3}\right)(1.6: 1$, $v / v)$ the above prepared solvent solution. One hundred microliters of the internal standard solution, i.e., cholesterol at a concentration of $0.1 \mathrm{M}$ in the aforementioned NMR solvent mixture, were added. $50 \mathrm{mg}$ of $\mathrm{Cr}(\mathrm{III})$ acetyl acetonate were added as relaxation agent to this solution, followed by $100 \mu \mathrm{L}$ of 2-chloro-4,4,5,5-tetramethyl-1,3,2-dioxa-phospholane (Cl-TMDP). After stirring for $120 \mathrm{~min}$ at ambient temperature, ${ }^{31} \mathrm{P}$ NMR spectra are recorded on a Bruker $400 \mathrm{MHz}$ NMR spectrometer controlled by TopSpin software, using an inverse gated decoupling technique with the probe temperature set to $20^{\circ} \mathrm{C}$. The maximum standard deviation of the reported data is $0.02 \mathrm{mmoL} \mathrm{g}^{-1}$, while the maximum standard error is $0.01 \mathrm{mmoL} \mathrm{g}^{-1}$. NMR data were processed with MestreNova (Version 8.1.1, Mestrelab Research, Santiego de Compostela, Spain). Technical loadings are determined by comparing the abundancies of total aromatic hydroxyl groups of the product lignin with the starting lignin.

\subsubsection{Qualitative ${ }^{1} \mathrm{H}^{-13} \mathrm{C}$ HSQC Analysis}

Samples of around $90 \mathrm{mg}$ were dissolved in $600 \mu \mathrm{L}$ DMSO-d6; chromium acetyl acetonate was added as spin-relaxing agent at a final concentration of ca. $1.5-1.75 \mathrm{mg} \mathrm{mL}^{-1}$. HSQC spectra were recorded at $27{ }^{\circ} \mathrm{C}$ on a Bruker $400 \mathrm{MHz}$ instrument equipped with TopSpin 2.1 software. ${ }^{1} \mathrm{H}-{ }^{13} \mathrm{C}$ HSQC spectra were obtained applying the following parameters for acquisition: TD = 2048 (F2), 512 (F1). The Bruker hsqcetgp pulse program in DQD acquisition mode was used, with NS $=32$; $\mathrm{TD}=2048$ (F2), 512 (F1); SW = 15.0191 ppm (F2), 149.9819 ppm (F1); O2 (F2) = 2000.65 Hz, O1 (F1) = $7545.96 \mathrm{~Hz}$; $\mathrm{D} 1=2 \mathrm{~s} ;$ CNST2 $(1 \mathrm{~J}(\mathrm{C}-\mathrm{H})=145 ;$ acquisition time F2 channel $=85.1968 \mathrm{~ms}$, F1 channel $=8.4818 \mathrm{~ms}$; pulse length of the $90^{\circ}$ high power pulse P1 was optimised for each sample. NMR data were processed 
with MestreNova; spectra were referenced to the residual signals of DMSO-d6 (2.49 ppm for ${ }^{1} \mathrm{H}$ and $39.5 \mathrm{ppm}$ for ${ }^{13} \mathrm{C}$ domain, respectively).

\subsubsection{Thermogravimetric Analysis}

The lignin samples were firstly crushed to a fine powder in a mortar with a ceramic pestle. The thermal decomposition of lignin samples was determined using an atmospheric thermogravimetric instrument (Mettler Toledo, Columbus, OH, USA). The pyrolysis of lignin samples was investigated in $100 \%$ volume fraction $\mathrm{N}_{2}\left(100 \mathrm{~cm}^{3} \mathrm{~min}^{-1}\right.$ of $\mathrm{N}_{2}$ measured at $20^{\circ} \mathrm{C}$ and $\left.101.3 \mathrm{kPa}\right)$. The reactivity of lignin samples in $20 \%$ volume fraction $\mathrm{CO}_{2}\left(20 \mathrm{~cm}^{3} \mathrm{~min}^{-1}\right.$ of $\mathrm{CO}_{2}$ and $80 \mathrm{~cm}^{3} \mathrm{~min}^{-1}$ of $\mathrm{N}_{2}$ measured at $20{ }^{\circ} \mathrm{C}$ and $\left.101.3 \mathrm{kPa}\right)$ and $5 \%$ volume fraction $\mathrm{O}_{2}\left(5 \mathrm{~cm}^{3} \mathrm{~min}^{-1}\right.$ of $\mathrm{O}_{2}$ and $95 \mathrm{~cm}^{3} \mathrm{~min}^{-1}$ of $\mathrm{N}_{2}$ measured at $20^{\circ} \mathrm{C}$ and $101.3 \mathrm{kPa}$ ) was determined by loading $5 \mathrm{mg}$ of sample in an $\mathrm{Al}_{2} \mathrm{O}_{3}$ crucible. The lignin samples were firstly heated up to $110{ }^{\circ} \mathrm{C}$ and kept for $30 \mathrm{~min}$ isothermally for drying. The dried samples were subsequently heated to $1100{ }^{\circ} \mathrm{C}$ at a constant heating rate of $10^{\circ} \mathrm{C} \mathrm{min}-1$. All measurements were conducted in duplicate to verify sufficient reproducibility.

\section{Results and Discussion}

\subsection{Ultimate and Proximate Analysis}

The ultimate and proximate analysis of fractionated lignin was carried out and the results are shown in Table 1. Organosolv lignin fractions were free from sulphur, confirming previous results [30]. Table 1 shows carbon $(\mathrm{C})$, oxygen $(\mathrm{O})$, hydrogen $(\mathrm{H})$, nitrogen $(\mathrm{N})$ and sulphur $(\mathrm{S})$ contents of all lignins according to CHNS analyzer. The carbon content of lignin from sweet sorghum bagasse was slightly lower than that of lignin samples from other feedstocks. Nitrogen content found in lignin reflects contamination by residues of proteins or industrial fertilisers, especially in the case of the annual plant-derived sorghum and cotton lignins. In most lignins except pine sawdust lignin, nitrogen amount is in the range of $0.4-1.1 \mathrm{wt}$. $\%$ [31,32].

Table 1. Proximate and ultimate analysis of lignin that was fractionated from cotton, sweet sorghum, pine sawdust, spruce bark (with and without the acid catalyst). The abbreviations of lignin fractionated from pine sawdust (PL), cotton stalks (CL), sweet sorghum bagasse (SSL), spruce bark with (SBAL) and without acid addition (SBNL) were used. The standard error for all measurements was $<10 \%$ of the value.

\begin{tabular}{lccccc}
\hline Properties & PL & CL & SSL & SBAL & SBNL \\
\hline \multicolumn{7}{c}{ Proximate and ultimate analysis } & \% on dry basis) \\
\hline Moisture $^{\text {a }}$ & 2.1 & 0.1 & 0.4 & 0.1 & 0.2 \\
\hline $\mathrm{C}$ & 65.2 & 64.9 & 61.9 & 66.5 & 64.6 \\
\hline $\mathrm{H}$ & 6.3 & 7.0 & 5.9 & 6.7 & 6.4 \\
\hline $\mathrm{O}$ & 28.0 & 26.3 & 31.0 & 25.8 & 27.8 \\
\hline $\mathrm{N}$ & 0.4 & 1.7 & 1.1 & 0.9 & 1.1 \\
\hline $\mathrm{S}$ & 0.1 & 0.1 & 0.1 & 0.1 & 0.1 \\
\hline \multicolumn{5}{c}{${ }^{\mathrm{a}}$ wt. \% (as received). }
\end{tabular}

Table 2 shows the results of analyses of impurities, cellulose and hemicellulose sugars and ash in the various lignins, determined according to the NREL technical report [33]. The results indicate that lignin samples are of high purity, exhibiting only low ash and carbohydrate contents. Specifically, the highest carbohydrate impurities were observed in SSL and reached $7 \% w / w$, whereas for the rest of lignins it was less than $2.3 \% w / w$. The ash content in all lignin samples was less than $0.6 \% w / w$, with most of the samples to be below $0.3 \% w / w$ (Table 2). 
Table 2. Composition in impurities $(\%, w / w)$ and GPC analysis of the lignin samples. The abbreviations of lignin fractionated from pine sawdust (PL), cotton stalks (CL), sweet sorghum bagasse (SSL), spruce bark with (SBAL) and without acid addition (SBNL) were used. The standard error for all measurements was $<10 \%$ of the value.

\begin{tabular}{lcccccc}
\hline \multirow{2}{*}{ Feedstock } & Cellulose & \multicolumn{2}{c}{ Hemicellulose Ash } & $\mathbf{M}_{\boldsymbol{n}}$ & $\mathbf{M}_{\boldsymbol{w}}$ & \multirow{2}{*}{ PDI } \\
\cline { 2 - 6 } & \multicolumn{5}{c}{$\boldsymbol{\%}, \boldsymbol{w} / \boldsymbol{w}$} & \multicolumn{3}{c}{ Da } \\
\hline PL & 0.2 & 0.9 & 0.2 & 1900 & 7700 & 4.4 \\
\hline CL & 0.3 & 0.6 & 0.2 & 3400 & 16,800 & 4.9 \\
\hline SSL & 4.1 & 2.9 & 0.3 & 1600 & 6600 & 4.1 \\
\hline SBAL & 1.5 & 0.7 & 0.6 & 1600 & 10,600 & 6.6 \\
\hline SBNL & 1.5 & 0.6 & 0.2 & 1600 & 8900 & 5.6 \\
\hline
\end{tabular}

\subsection{GPC Analysis}

The molecular weight of lignin samples is given in Table 2. The lignin number average molecular weight $\left(\mathrm{M}_{n}\right)$ varied from 1600 to $3400 \mathrm{Da}$ with the highest weight for the cotton stalk lignin. The size exclusion analysis showed a broad variation of the weight average molecular weight $\left(\mathrm{M}_{w}\right)$ from 6600 to $16,800 \mathrm{Da}$, emphasizing eventually the effect of feedstock and the structural characteristics between the lignins of the various feedstocks in combination with the fractionation protocol applied. In general, the molecular weight found for the lignin samples can be attributed to the milder reaction conditions of the organosolv treatment used in the present study. Overall, lower number average molecular weight samples exhibited also a lower polydispersity, corresponding to previous results [34-37].

\subsection{FTIR Analysis}

FTIR analysis was conducted to investigate the differences in main functional groups and monomer composition in the tested lignin samples, as shown in Figure 1; band assignments are summarized in the Appendix A (Table A1).

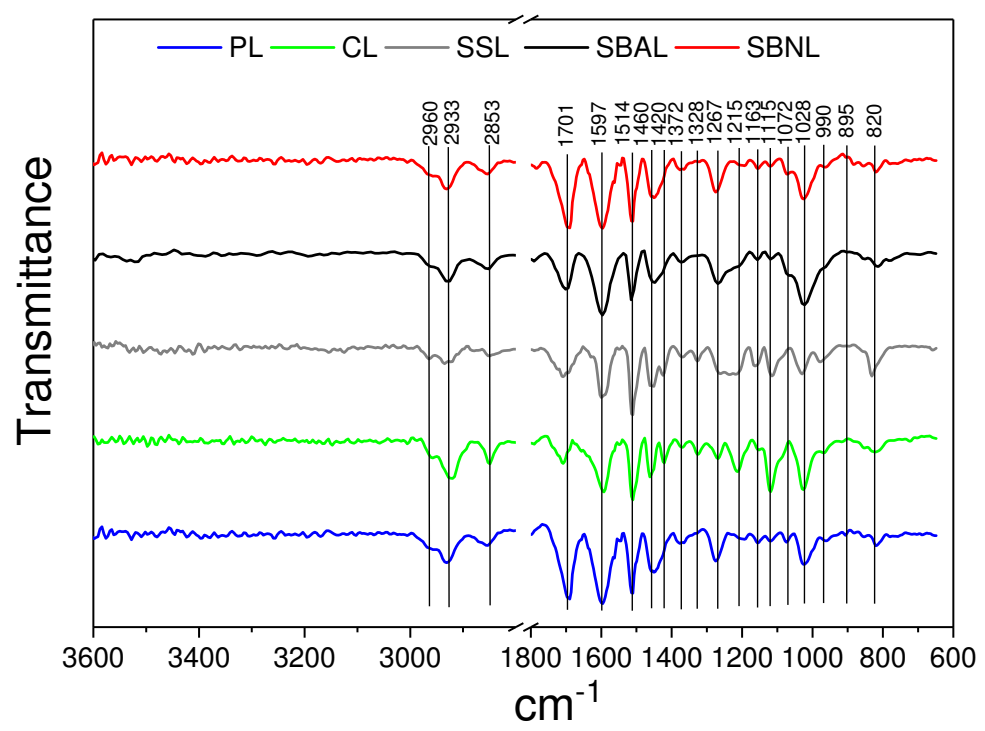

Figure 1. Experimental IR spectra of lignin samples. The abbreviations of lignin fractionated from pine sawdust (PL), cotton stalks (CL), sweet sorghum bagasse (SSL), spruce bark with (SBAL) and without acid addition (SBNL) were used. 
The bands at 1514 and $1597 \mathrm{~cm}^{-1}$ were significantly pronounced in all lignin samples and represent the aromatic skeletal vibrations [38,39]. All organosolv lignins from the different feedstocks presented the vibration of $\mathrm{C}-\mathrm{H}$ stretching in $-\mathrm{CH}_{2}-$ and $-\mathrm{CH}_{3}$ group at $2960-2933$ and $2853 \mathrm{~cm}^{-1}$, respectively, as well as the $\mathrm{C}=\mathrm{O}$ group stretching of carbonyl groups of $\alpha$-oxidized structural motifs with bands at $1694-1701 \mathrm{~cm}^{-1}$. Aromatic skeletal vibrations at $1514 \mathrm{~cm}^{-1}, \mathrm{C}-\mathrm{H}$ deformations in $\mathrm{CH}_{2}$ and $\mathrm{CH}_{3}$ group (1450-1460 $\left.\mathrm{cm}^{-1}\right)$, aliphatic $\mathrm{C}-\mathrm{H}$ stretch in $\mathrm{CH}_{3}$, not in $\mathrm{OCH}_{3}\left(1372 \mathrm{~cm}^{-1}\right), \mathrm{G}$ ring breathing $\left(1267-1272 \mathrm{~cm}^{-1}\right)$, and aromatic C-H in plane deformation $(\mathrm{G}>\mathrm{S})\left(1028 \mathrm{~cm}^{-1}\right)$ can be observed in all lignin samples with different intensities. The intensity of the guaiacyl unit in CL and SSL was represented by the peak at C-C and C-O stretch. FTIR absorptions indicative of syringyl units were found to be stronger in CL and SSL, as one would expect based on the type of feedstock.

\section{4. ${ }^{31} \mathrm{P}$ NMR and ${ }^{1} \mathrm{H}^{-13} \mathrm{C}$ HSQC Analysis}

Quantitative ${ }^{31} \mathrm{P}$ NMR analyses of the lignins under study reveal structural differences and dominating types of aromatic structures given the starting biomasses. Results are summarized in Table 3.

Table 3. ${ }^{31} \mathrm{P}$ NMR analysis of lignin samples. The abbreviations of lignin fractionated from pine sawdust (PL), cotton stalks (CL), sweet sorghum bagasse (SSL), spruce bark with (SBAL) and without acid addition (SBNL) were used.

\begin{tabular}{|c|c|c|c|c|c|c|c|c|}
\hline \multirow{3}{*}{ Lignin } & \multirow{2}{*}{ Aliph $\mathrm{OH}$} & \multicolumn{4}{|c|}{ Aromatic $\mathrm{OH}$} & \multirow{2}{*}{$\begin{array}{c}\text { Acidic } \\
\mathrm{OH}\end{array}$} & \multirow{3}{*}{$\begin{array}{c}\text { Total } \\
\mathrm{OH} \\
\mathrm{mmoL} \mathrm{g}^{-1}\end{array}$} & \multirow{3}{*}{$\begin{array}{c}\text { Arom/Aliph } \\
\text { OH }\end{array}$} \\
\hline & & Cond & G & $\mathrm{p}-\mathrm{OH}$ & Total & & & \\
\hline & $\mathrm{mmoL} \mathrm{g}^{-1}$ & \multicolumn{4}{|c|}{$\mathrm{mmoL} \mathrm{g}^{-1}$} & $\operatorname{mmoL~}^{-1}$ & & \\
\hline PL & 1.41 & 0.32 & 0.58 & 0.06 & 0.96 & 0.16 & 2.37 & 0.68 \\
\hline $\mathrm{CL}$ & 1.06 & 0.46 & 0.41 & 0.14 & 1.00 & 0.26 & 2.06 & 0.95 \\
\hline SSL & 1.64 & 0.55 & 0.39 & 0.45 & 1.39 & 0.27 & 3.03 & 0.85 \\
\hline SBAL & 0.83 & 0.39 & 0.45 & 0.36 & 1.21 & 0.32 & 2.04 & 1.46 \\
\hline SBNL & 0.87 & 0.25 & 0.43 & 0.32 & 1.01 & 0.31 & 1.88 & 1.16 \\
\hline
\end{tabular}

Noteworthy, only the two bark lignin samples exhibit more phenolic $\mathrm{OH}$ than aliphatic $\mathrm{OH}$, with a significant difference in the SBAL sample. The positive effect of the presence of the acid catalyst with respect to generating free phenolics is obvious in this case. The higher amounts of S-type-phenolics found for CL and SSL reflect the presence of the syringyl monomers in the structure, while overall notable presence of condensed units suggests that the treatment might cause, to a low extend, intramolecular condensations.

HSQC spectra of lignins were acquired using fixed, standardised conditions in terms of concentrations of samples and acquisition parameters to allow a comparative analysis without quantification. Non-acetylated samples were dissolved in DMSO for analysis. Results are summarized in Table 4. HSQC-analyses essentially confirm structural differences of the lignins as it can be expected based on the starting biomasses. In terms of monomer composition, PL which has been chosen as a base for its essentially 'pure $G$ ' character compared to the other samples, shows the typical G-units as essentially only monomer type present, and the presence of typical interunit binding motifs. Cross peaks indicative for $\alpha$-oxidized $\beta-O-4^{\prime}$ motifs are present. Cinnamyl alcohol and aldehyde are detectable end motifs in PL. The overall intensities of cross-peaks in the lower aliphatic region, eventually attributable to the presence of further extractable aliphatic impurities and aliphatic end groups of various nature are comparable to those found for CL and SSL, but inferior to those of the bark samples. Traces of hemicellulose residues, especially xylan residues, in the lignin are detectable, signs indicative of lignin-carbohydrate complexes (LCCs) in PL are de facto absent. CL shows the 
typical distribution of monomer types for herbaceous lignins, and standard interunit motifs are present as well as typical termination motifs. Cross peaks indicative for $\alpha$-oxidized $\beta$-O- $4^{\prime}$ motifs are less intense than for PL. Traces of hemicellulose residues in the lignin are detectable, signs indicative of lignin-carbohydrate complexes (LCCs) are absent here as well. The sample contains a significant amount of para-coumarates as one could expect compared to PL.

A more densely populated aliphatic region indicates the presence of larger amounts of extractives in the sample compared to PL. Moreover, SSL contains still some extractives/aliphatics but in overall lower concentrations when normalizing abundancies to PL. Apart from standard monomer units for this lignin, the sweet sorghum bagasse sample contains the standard bonding motifs, seemingly in less abundance than PL and CL. However, given the fact that the sample due to the presence of the S-units, contains significantly more methoxy groups per C9-unit, differences as highlighted in Table 4 must not be overinterpreted. Nevertheless, coumarate residues can be seen as significantly enhanced also with respect to CL. The sample contains significantly higher concentrations of hemicellulose residues than PL and CL.

Both bark extracts, i.e., SBAL and SBNL, give rather different HSQC spectra compared to the other lignin samples as is expectable. The two samples are overall very similar, showing mainly $\beta-O-4^{\prime}$ and $\beta-O-5^{\prime}$ interunit bondings. The clear presence of LCC-indicating cross-peaks in SBNL vs. traces of these peaks in SBAL is in agreement with the ${ }^{31} \mathrm{P}$ NMR findings discussed above, hinting at the effectiveness of the acid treatment for eventually cleaving LCC bonding motifs and facilitating thus removal of carbohydrates. Both bark samples are characterized by high intensities of cross-peaks in the lower aliphatic region, eventually attributable to the presence of higher amounts of polar extractable impurities. 
Table 4. Summary of identified structural motifs in the lignins under study based on HSQC-analyses. PL has been set as base for comparison across all samples; SBAL and SBNL compared directly. The abbreviations of lignin fractionated from pine sawdust (PL), cotton stalks (CL), sweet sorghum bagasse (SSL), spruce bark with (SBAL) and without acid addition (SBNL) were used.

\begin{tabular}{|c|c|c|c|c|c|c|c|c|c|}
\hline \multirow{2}{*}{ Bonding Motif } & $\delta{ }^{1} \mathbf{H}$ & $\delta^{13} \mathrm{C}$ & \multicolumn{5}{|c|}{ Comparison to PL, \% } & \multicolumn{2}{|c|}{ Comparison SBAL, SBNL, \% } \\
\hline & \multicolumn{2}{|c|}{ ppm } & PL & CL & SSL & SBAL & SBNL & SBAL & SBNL \\
\hline $\mathrm{H} 2,6-\mathrm{H}$ & 7.23 & 128.23 & 0.86 & 0.85 & 1.13 & 1.52 & 1.27 & 2.17 & -0.10 \\
\hline G2-H & 7.00 & 110.64 & 13.34 & -0.47 & -0.74 & -0.29 & -0.45 & 9.47 & -0.23 \\
\hline $\mathrm{S} 2,6-\mathrm{H}$ & 6.72 & 103.65 & 1.71 & 5.10 & 3.29 & 0.28 & 0.02 & 2.19 & -0.20 \\
\hline $\mathrm{H} \gamma$ in cinn-OH & 4.04 & 59.85 & 1.34 & 1.82 & 0.75 & 4.72 & 4.37 & 7.67 & -0.06 \\
\hline $\mathrm{H} \alpha$ in $\beta-O-4^{\prime}$ & 4.87 & 71.35 & 3.33 & 0.26 & -0.47 & -0.46 & -0.47 & 1.79 & -0.02 \\
\hline $\mathrm{H} \beta$ in $\beta-O-4^{\prime}$ & 4.34 & 83.12 & 3.57 & -0.41 & -0.69 & -0.55 & -0.55 & 1.62 & -0.01 \\
\hline $\mathrm{H} \beta$ in $\beta-O-4^{\prime} \alpha-\mathrm{C}=\mathrm{O}$ G & 7.48 & 110.83 & 1.14 & -0.15 & -0.54 & -0.18 & -0.43 & 0.94 & -0.31 \\
\hline $\mathrm{H} \alpha$ in $\beta-5^{\prime}$ & 5.47 & 86.74 & 2.35 & -0.51 & -0.84 & -0.50 & -0.55 & 1.18 & -0.10 \\
\hline $\mathrm{H} \alpha$ in $\beta-\beta^{\prime}$ & 4.65 & 85.11 & 0.68 & 0.34 & -0.71 & -0.40 & -0.22 & 0.41 & 0.29 \\
\hline $\mathrm{H} \beta$ in $\beta-\beta^{\prime}$ & 3.06 & 53.66 & 1.21 & 0.31 & -0.67 & 0.03 & -0.04 & 1.25 & -0.07 \\
\hline $\mathrm{H} \beta$ in epi- $\beta-\beta^{\prime}$ & 2.86 & 53.61 & 0.55 & -0.04 & -0.73 & -0.09 & -0.29 & 0.50 & -0.22 \\
\hline benzaldehyde & 6.84 & 126.49 & 0.57 & -0.84 & -0.81 & 4.98 & 4.89 & 3.41 & -0.01 \\
\hline G-hydroxyethylketone & 1.24 & 21.93 & 7.49 & 0.16 & -0.74 & 0.95 & 0.58 & 14.57 & -0.19 \\
\hline Aryl ethyl ketone & 2.21 & 33.2 & 2.37 & 3.27 & 0.02 & 7.57 & 5.80 & 20.31 & -0.21 \\
\hline Cinnamyl aldehyde & 6.96 & 123.8 & 0.61 & -0.79 & -0.87 & 4.41 & 4.15 & 3.30 & -0.05 \\
\hline FA-H6 & 7.16 & 123.97 & 0.92 & -0.60 & -0.61 & 3.14 & 3.01 & 3.81 & -0.03 \\
\hline PCE-H2,6 & 7.47 & 129.91 & 0.23 & 0.65 & 21.17 & 1.35 & 2.04 & 0.54 & 0.30 \\
\hline \multirow{3}{*}{ xylan signals } & 3.05 & 72.47 & & & & & & & \\
\hline & 3.29 & 73.64 & 0.36 & 0.31 & 2.57 & 0.99 & 1.11 & 0.73 & 0.10 \\
\hline & 3.52 & 75.26 & & & & & & & \\
\hline
\end{tabular}




\subsection{Headspace Gas Chromatography-Mass Spectrometry}

The formation of main compounds during HSGC-MS treatment of lignin was investigated at treatment temperatures of 110,180 and $270{ }^{\circ} \mathrm{C}$. Only compounds with a spectral match quality greater than $85 \%$ and an abundance of greater than $0.5 \%$ are listed in the Table 5 .

The HSGC-MS analysis at $110{ }^{\circ} \mathrm{C}$ indicated only a few compounds in the vapor of lignin samples: Isovanilline in CL, PL, SSL, vanillin in SBNL and SBAL, eugenol in PL, coumaran, $\alpha$-curcumene, $o$-guaiacol and succinic acid in CL, cadelene in SBAL, CL and PL. The presence of coumaran in CL agrees with the literature as lignin in grasses generally contains significant greater amount of coumaryl (H) (5-35\%) than in softwoods [40]. The detected vanillin-based compounds represent the G-group unit [41]. The increase of vanillin concentration during the heating is the result of the oxidative degradation of guaiacyl structures [42]. The other released aromatic compounds, i.e., isovanilline, etc., have other aromatic origins or can be seen as products of more complex degradation/migration and rearrangements occuring upon heating under air. The relative amounts of vanillin were less abundant in CL and SSL for the reason of smaller proportion of guaiacyl units in herbaceous biomass than in softwood. Both bark lignin samples retain greater concentrations of extractives bonded to their structure than other samples, as the results listed in Table 5 show. Even using the additional ethanol-water or water-diethyl ether washing of lignin indicated that extractives can remain partially linked to lignin fibers due to their affinity [43]. In addition, previous results showed that $\alpha$-curcumene and cadelene could be formed during low temperature heating of resins [44]. The most abundant fragment released during HSGC-MS analysis was calamenene in SBNL and SBAL and PL samples, which were previously found in the released compound vapor of coniferous wood [45]. This result agrees with the thermogravimetric analysis of lignin samples, whereas lignins fractionated from softwood showed a pronounced DTG peak at low temperatures, as discussed in Section 3.6. Overall, cotton stalks lignin showed the broadest distribution of released compounds during headspace analysis at $110^{\circ} \mathrm{C}$.

An increase in heat treatment temperature from $110^{\circ} \mathrm{C}$ to $180^{\circ} \mathrm{C}$ and then $270{ }^{\circ} \mathrm{C}$ during HSGC-MS analysis led to an increase in aromatic compounds and esters, and decrease in aldehydes which mainly originated from remaining impurities of hemicellulose and cellulose, as previously discussed [46]. The ethyl levulinate found in SSL, SBNL, SBAL and CL and dehydroabietal detected in SSL were released at $180^{\circ} \mathrm{C}$, emphasizing the presence of cellulose-related compounds, which were, however, not observed any more at $270{ }^{\circ} \mathrm{C}$. Moreover, HSGC-MS treatment at $180^{\circ} \mathrm{C}$ led to the formation of 5-formylfurfural in SBNL, SBAL, and SSL, confirming the presence of hemicellulose-related species, in accordance with HSQC data. This result agrees with the thermogravimetric analysis (see Section 3.6), whereas both bark lignins showed a pronounced DTG peak at low temperatures that indicates the presence of remaining extractives and carbohydrates. Results further indicate that compounds in the vapor phase at $270{ }^{\circ} \mathrm{C}$ analysis were mainly oxygenated aromatic chemicals. The main products in the HSGC-MS analysis of SSL, PL, SBAL, SBNL and CL at $270{ }^{\circ} \mathrm{C}$ were vanillin, acetovanillone and $o$-guaiacol, stemming from G-based structural units. Isoeugenol, 4-ethylguaiacol, vanillin and methyl vanillate were present in all lignin samples, with noteworthy exception of SBAL, whereas 4-vinylguaiacol was detected in all lignin samples with the exception of both spruce bark lignins. These results are in agreement with data of thermogravimetric analyses indicating an increased release of guaiacol and its derivatives with higher heating temperatures. At 180 and $270{ }^{\circ} \mathrm{C}$, all lignin samples, except PL at both temperatures and CL at $270{ }^{\circ} \mathrm{C}$, formed succinic acid, stemming from oxidative cleavage under the severe conditions. 
Table 5. List of identified compounds from HSGC-MS analysis at headspace oven temperature of $110,180,270{ }^{\circ} \mathrm{C}$ of lignin fractionated from pine sawdust (PL), cotton stalks (CL), sweet sorghum (SSL), spruce bark with an acid catalyst (SBAL) and spruce bark without the acid catalyst (SBNL).

\begin{tabular}{|c|c|c|c|c|}
\hline \multirow{2}{*}{ No } & \multirow{2}{*}{ Compound } & \multicolumn{3}{|c|}{ Presence with More than $0.5 \%$ of Total Amount in Lignin Samples at T Equal } \\
\hline & & $110^{\circ} \mathrm{C}$ & $180^{\circ} \mathrm{C}$ & $270^{\circ} \mathrm{C}$ \\
\hline 1 & Acetosyringone & & & PL \\
\hline 2 & Acetovanillone & & & SSL, PL, CL, SBNL, SBAL \\
\hline 3 & 5-Acetoxymethyl-2-furaldehyde & & & PL \\
\hline 4 & 4-Acetylsyringol & & SSL, CL, PL, BNL & SSL, CL \\
\hline 5 & 1,2-Benzenediol & & CL, SBNL, SBAL & \\
\hline 6 & Benzoic acid & & & PL \\
\hline 7 & Cadelene & SBAL, CL, PL & SBNL, SBAL & SBNL \\
\hline 8 & $\alpha$-Calacorene & & SBAL & \\
\hline 9 & Calamenene & SBAL, SBNL, PL & SBAL, SBNL, PL & SBAL, SBNL, PL \\
\hline 10 & $\gamma$-Caprolactone & & & $\mathrm{CL}$ \\
\hline 11 & $\gamma$-Carboethoxy- $\gamma$-butyrolactone & & SBAL, CL & \\
\hline 12 & Cembrene & & SBNL & \\
\hline 13 & Coumaran & $\mathrm{CL}, \mathrm{SSL}$ & CL, SSL & \\
\hline 14 & $\alpha$-Curcumene & $\mathrm{CL}$ & & \\
\hline 15 & Decanal & & & SBAL, SBNL \\
\hline 16 & 2-Decanone & & & CL \\
\hline 17 & Dehydroabietal & & SBAL, SBNL & \\
\hline 18 & Dehydroabietan & & SBAL, SSL & \\
\hline 19 & Dihydroeugenol & & & PL \\
\hline 20 & Ethyl coumarate & & & SSL, SBNL \\
\hline 21 & Ethyl DL-malate & & SSL, SBAL, SBNL & \\
\hline 22 & Ethyl elaidate & & SSL, CL & \\
\hline 23 & Ethyl heptadecanoate & & SBAL, SBNL & \\
\hline
\end{tabular}


Table 5. Cont.

\begin{tabular}{|c|c|c|c|c|}
\hline \multirow{2}{*}{ No } & \multirow{2}{*}{ Compound } & \multicolumn{3}{|c|}{ Presence with More than $0.5 \%$ of Total Amount in Lignin Samples at T Equal } \\
\hline & & $110^{\circ} \mathrm{C}$ & $180^{\circ} \mathrm{C}$ & $270^{\circ} \mathrm{C}$ \\
\hline 24 & Ethyl homovanillate & & & SSL \\
\hline 25 & Ethyl levulinate & & CL, SBAL, SBNL, SSL & \\
\hline 26 & Ethyl linolenate & & SBAL, CL & $\mathrm{CL}$ \\
\hline 27 & Ethyl oleate & & SBNL, CL & \\
\hline 28 & Ethyl pentadecanoate & & SSL & \\
\hline 29 & Ethyl pyroglumate & & SSL & \\
\hline 30 & 4-Ethylguaiacol & & SSL, SBNL, SBAL & SSL, SBNL, CL, PL \\
\hline 31 & Ethylhexyl benzoate & & & PL \\
\hline 32 & Eugenol & PL & & \\
\hline 33 & 4-Ethylphenol & & SSL, SBNL, SBAL, CL & SBAL, CL, SSL \\
\hline 34 & Ferulic acid ethyl ester & & SSL & SSL, CL \\
\hline 35 & 5-Formylfurfural & & SBAL, SBNL, SSL & \\
\hline 36 & 4-Formylphenol & & PL & SSL, PL \\
\hline 37 & 2-Furoic acid & & SBAL & SBNL \\
\hline 38 & Guaiacylacetone & & SSL, CL & SSL, SBNL, CL \\
\hline 39 & 5-Hydroxymethylfurfural & & SSL, PL, SBAL & SSL, PL \\
\hline 40 & Isoeugenol & $\mathrm{CL}$ & CL, SBNL, SBAL, PL, SSL & SSL, SBNL, CL, PL \\
\hline 41 & 8-Isopropyl-1,3-dimethylphenanthrene & & & PL \\
\hline 42 & Isovanilline & CL, PL, SSL & & PL \\
\hline 43 & Levoglucosan & & & SBNL \\
\hline 44 & Methoxyeugenol & & & SSL, CL, SBNL \\
\hline 45 & (1-Methoxy-pentyl)-cyclopropane & SBAL, SBNL & SBNL & \\
\hline 46 & Methyl dehydroabiatate & & PL & SBAL, SBNL \\
\hline 47 & Methyl pimarate & & & SBNL, SSL \\
\hline 48 & Methyl vanillate & & & SSL, PL, CL, SBNL \\
\hline 49 & Mono(2-ethylhexyl)phthalate & & SSL, PL, SBAL, CL & SSL, PL, SBAL, CL \\
\hline
\end{tabular}


Table 5. Cont.

\begin{tabular}{|c|c|c|c|c|}
\hline \multirow{2}{*}{ No } & \multirow{2}{*}{ Compound } & \multicolumn{3}{|c|}{ Presence with More than $0.5 \%$ of Total Amount in Lignin Samples at T Equal } \\
\hline & & $110^{\circ} \mathrm{C}$ & $180^{\circ} \mathrm{C}$ & $270^{\circ} \mathrm{C}$ \\
\hline 50 & Naphthalene & & & SBAL \\
\hline 51 & Nonanal & & SBAL & SBAL, PL \\
\hline 52 & Nonanoic acid & & CL & CL \\
\hline 53 & 9,12-Octadecadienoic acid & & SSL & SSL \\
\hline 54 & Octadecenoic acid & & & SSL, SBNL \\
\hline 55 & $o$-Guaiacol & CL & CL, PL, SSL, SBNL, SBAL & CL, PL, SSL, SBNL, SBAL \\
\hline 56 & $o$-Pyrocatechualdehyde & & SBAL, SBNL & \\
\hline 57 & 4-Oxononanal & & & $\mathrm{CL}$ \\
\hline 58 & Palmitic acid & & & SBAL, CL \\
\hline 59 & Palmitic acid ethyl ester & $\mathrm{CL}$ & SBAL, SSL, SBNL, CL & SBAL, SSL, SBNL, CL \\
\hline 60 & $p$-cresol & & & PL, SSL \\
\hline 61 & $p$-Formylphenol & & & CL \\
\hline 62 & Propenal & & & SSL, PL \\
\hline 63 & 3-Pyridinol & & SSL & SBNL, CL \\
\hline 64 & Retene & & SSL, SBAL, SBNL, CL, PL & SSL, SBAL, SBNL, CL, PL \\
\hline 65 & Succinic acid & $\mathrm{CL}$ & CL, SBNL, SBAL, SSL & SBAL, SBNL, SSL \\
\hline 66 & Syringa aldehyde & & SSL, CL & SSL \\
\hline 67 & Syringaldehyde & & SSL, CL, PL & \\
\hline 68 & Syringol & & $\mathrm{CL}$ & $\mathrm{CL}$ \\
\hline 69 & Tetradecanal & & & $\mathrm{CL}$ \\
\hline 70 & 2-Tetradecanone & & & $\mathrm{CL}$ \\
\hline 71 & 2-Undecanone & & & $\mathrm{CL}$ \\
\hline 72 & Vanillin & SBNL, SBAL & SSL, CL, PL & SBNL, SSL, SBAL, CL, PL \\
\hline 73 & 4-Vinylguaiacol & CL & SSL, CL, PL, SBNL, SBAL & SSL, CL, PL \\
\hline
\end{tabular}


The major difference of CL and SSL to other samples lies in the presence of acetylsyringol and ferulic acid ethyl ester in their structure confirming the typical presence of dimethoxyphenols for these lignins. Ferulate and coumarate esters present the major part of LCC linkages in herbaceous biomass which can produce ester linkage with polysaccharides and proteins due to the presence of carboxylic acid groups at the end of propenyl groups [47]. In comparison to previous results, esterified fatty alcohols were detected in significant smaller numbers in this study, hinting at the effectiveness of the treatment in terms of removing these impurities [48,49].

No $p$-cresol was detected in cotton and spruce bark lignins. Free fatty acids were present in the range from palmitic to 13-octadecadienoic acid. The esterified fatty acids were detected in all lignin samples as impurities. In addition, the HSGC-MS analysis of all lignin samples at 180 and $270{ }^{\circ} \mathrm{C}$ showed the presence of retene in the vapor phase, indicating the presence of such lipid components as impurities in all lignin samples, including the lignin from herbaceous cotton stalks (CL). The presence of dihydroabietal at $180{ }^{\circ} \mathrm{C}$ in both spruce bark lignin samples and absence at $270{ }^{\circ} \mathrm{C}$ emphasizes the impact of temperature on the released products during HSGC-MS analysis as well as their potential stability limits.

\subsection{Thermogravimetric Analysis}

The thermogravimetric analysis showed that the conversion of all lignin samples was similar. The main difference in $\mathrm{O}_{2}$ and $\mathrm{CO}_{2}$ reactivity of lignin samples was observed in the higher maximum temperature of PL compared to other lignin samples due to the shift of the DTG peak to the higher temperatures. The DTG curves show a double broad peak that indicates a heterogeneous lignocellulosic mixture with respect to $\mathrm{O}_{2}$ and $\mathrm{CO}_{2}$ reactivity $[50,51]$.

The DTG peaks of lignin degradation can be interpreted on the basis of the above discussed structural differences between various lignin samples, taking into account also impurities [52]. In agreement with HSQC-analyses, the first DTG peak during pyrolysis ranging from 200 to $300^{\circ} \mathrm{C}$ can be referred to as the degradation of carbohydrates and contained extractives, i.e., fatty acids, pheromones, etc., as observed in the GC-MS headspace analysis, respectively. The second DTG peak located between 300 and $380^{\circ} \mathrm{C}$ can be associated with the presence of mixed HGS structures as common in CL and SSL, followed by the third DTG peak that can be seen as reflecting G-only, or G-dominant lignin structures as typical in PL, SBAL and SBNL between 375 and $500{ }^{\circ} \mathrm{C}$. The three DTG peaks indicate the development of three main components: A reactive carbon constituent, a carbon constituent with intermediate reactivity, and a less reactive carbon structure with reactivity that approaches that of commercial guaiacol [53]. The reactivities of lignin isolated from spruce bark with or without the use of the acid catalyst during the organosolv process were similar in terms of thermal characteristics, reflecting the basic structural similarity.

Data further underline the fact that both bark lignins have a similar composition. The first DTG peak was in absolute terms more visible for the bark lignins compared to other samples. This eventually reflects the greater amount of extractives remaining in the lignin after fractionation, as reported by the HSQC-analyses. SSL showed only a shoulder of the DTG peak with the maximum temperature shifted by $10^{\circ} \mathrm{C}$ to higher temperatures compared to both bark lignins. Accumulative analysis of the curves indicate that lignins fractionated from herbaceous species are thermally less stable than those of softwood, which is in line with previous results [54,55]. Interestingly, the thermal data do not seem to reflect the ratio of aliphatic to aromatic $\mathrm{OH}$-groups, or the impact of phenolic $\mathrm{OH}$-group content. Both bark lignin, i.e., SBAL and SBNL, exhibiting significantly more phenolic than aliphatic $\mathrm{OH}$-groups, show similar DTG curves compared to the other lignins. SBAL and SSL, representing the two lignins with the highest amount of phenolic $\mathrm{OH}$, do not show drastic differences to the other samples. 


\section{Discussion}

Thermogravimetric experiments demonstrated that the intrinsic reactivity of organosolv lignin under pyrolysis conditions or towards $\mathrm{O}_{2}$ and $\mathrm{CO}_{2}$ was similar due to the presence of DTG peaks in the same temperature range, with noteworthy exception of the PL sample. The PL sample was less reactive than other lignin samples. In principle, the reactivity of lignin can be affected by differences in organic composition and ash content [56,57]. However, the ash content of both spruce lignin SBAL and SBNL was below $0.6 \%, \mathrm{db}$, as shown in the proximate analysis (Table 2). Both bark lignin samples showed similar peak temperatures at 250 and $400{ }^{\circ} \mathrm{C}$. Moreover, the first DTG peak of ash lean CL is shifted to the lower temperatures emphasizing that the degradation of organosolv lignin strongly depends, apart from fundamental structural differences, on the remaining carbohydrates and extractives after fractionation and less on the ash content. The results have shown that lignins richer in guaiacol unit are less reactive than herbaceous lignins containing additionally $\mathrm{H}$ - and S-type phenolics, as shown in Figure $2 b$,c. This could be explained by the formation of large condensed and polyaromatic structures from guaiacol during heating of softwood lignin, whereas the HGS and GS lignins contain a high number of methoxy groups leading to less thermal stability on the basis of an altered reactivity $[58,59]$. On the basis of the array of lignins studied in here it is not possible, however, to identify points in the curves that would clearly reflect differences in phenolic $\mathrm{OH}$-group content or the ratio between aliphatic and aromatic OH-groups. Even when comparing G-lignin PL with structurally similar SBAL and SBNL, spectroscopically observed trends in terms of OH-group contents are not clearly delineable in thermogravimetric analysis.

The formation of levoglucosan found in case of SBNL indicates that an acid treatment is beneficial for facilitating removal of sugars in the generation of bark lignins. Simultaneously, the formation of phenols and lignin recondensation was enhanced during organosolv spruce bark fractionation using acid catalysts, as shown previously [60]. The presence of a catalyst promotes the cleavage of lignin aryl-ether bonds, releasing lignin fractions with lower molecular weight [61]. However, the reactivity of SBAL and SBNL samples in the thermal analysis was similar despite the differences in a polymer size and chemical composition in terms of impurities present. In addition, HSQC data suggest that the acid treatment in case of SBAL has no clear influence on the effectiveness of the hemicellulose removal. Chemical and HSQC-based analysis of SSL shows that sweet sorghum bagasse contains a higher concentration of polysaccharides impurities compared to the other lignin samples; however, headspace analysis did not reveal the formation of compounds that could be traced back to sugar residues. This finding is thus in line with the findings for carbohydrate-containing spruce bark lignins SBAL and SBNL. The literature reports a linkage between cellulose and lignin in spruce bark that is resistant to cleavage by sodium hydroxide [62]. Presence of sugar residues in the sample emphasizes, nevertheless, the more tedious process to extract the lignin from sweet sorghum bagasse. By means of purification techniques the residual polysaccharide content can be reduced by changing also the composition of the residual polysaccharides, e.g., glucose content decreases and the arabinose content increases due to the participation of this sugar in a lignin-polysaccharide linkage [63]. The compositional differences among lignins affected the distribution of weight losses during thermogravimetric analysis.

The results of this work demonstrate that the compositional differences among the lignin samples form the base for observed differences in the pyrolysis and $\mathrm{O}_{2} / \mathrm{CO}_{2}$ reactivity, as well as for the nature of released compounds during HSGC-MS analysis at different temperatures. The level of impurities in the organosolv lignin is generally low, and these low levels of remaining extractives and sugars in the lignins after organosolv fractionation do not affect the thermal stability of lignin; to a limited extend, however, they influence the formation of released products during HSGC-MS heating, leading to the formation of furfural-based products and the detection of fatty acids and derivatives. 


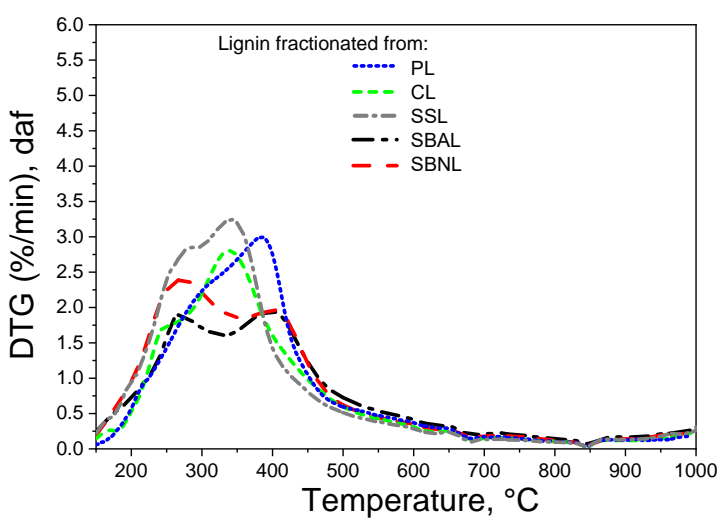

(a): Pyrolysis of lignin samples

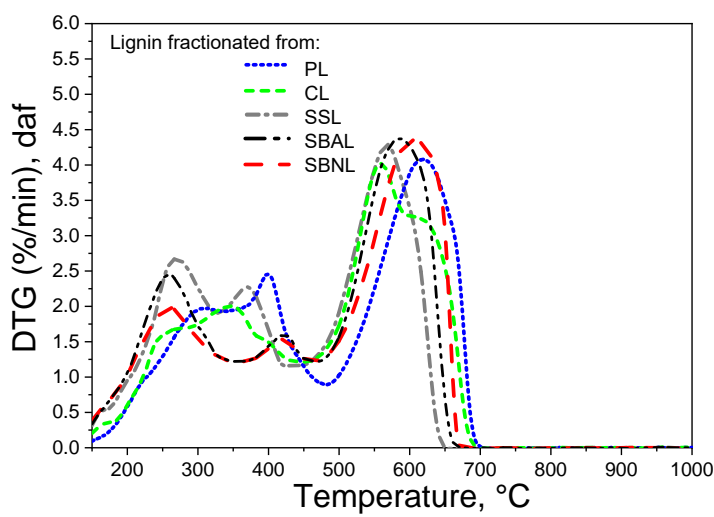

(b): Lignin samples in $\mathrm{O}_{2}$

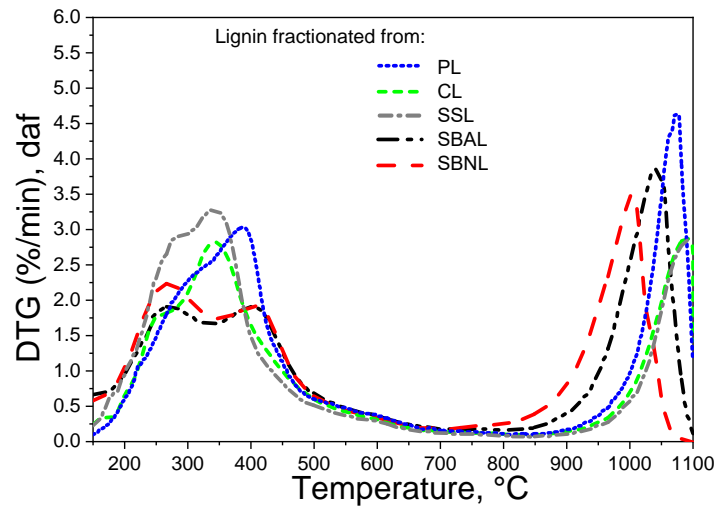

(c): Lignin samples in $\mathrm{CO}_{2}$

Figure 2. (a-c) DTG curves of lignin samples in $100 \% \mathrm{~N}_{2}, \mathrm{O}_{2}\left(5 \%\right.$ volume fraction $\mathrm{O}_{2}+95 \%$ volume fraction $\mathrm{N}_{2}$ ) and $\mathrm{CO}_{2}\left(20 \%\right.$ volume fraction $\mathrm{CO}_{2}+80 \%$ volume fraction $\left.\mathrm{N}_{2}\right)$. The abbreviations of lignin fractionated from pine sawdust (PL), cotton stalks (CL), sweet sorghum bagasse (SSL), spruce bark with (SBAL) and without acid addition (SBNL) were used.

\section{Conclusions}

Five organosolv lignins from two different classes of biomass were chemically and structurally analysed. Three softwood lignins and two herbaceous lignins were compared. Softwood lignin samples consisted of one main wood sample and two bark samples. These five lignins were analysed for impurities and structural features; the identified characteristics were correlated to data obtained in thermal treatment and gas phase analyses at various temperatures. The analysis of volatiles showed that the composition 
of the lignin backbones can be predicted in terms of a monomer type content. Presence of potential impurities, such as carbohydrates and fatty acids in original lignin can be identified using the head-space GC-MS analysis of volatiles. More interestingly, it was possible to correlate the general shape of the curves obtained in thermogravimetric analysis under various atmospheres to structural differences of lignins. These results suggest that G-type lignins can potentially be differentiated in HGS- and GS-lignins by comparison of mass loss curves, as long as they were isolated from the same biorefinery process, which yields lignins of comparable impurities. With respect to valorisation approaches, important differences in the relative amount of free phenolic $\mathrm{OH}$-groups, and/or their ratio to aliphatic $\mathrm{OH}$-groups in the side chains were not explicitly reflected, but contributed in a complex manner to the shape of mass loss curves.

Author Contributions: Conceptualization, A.T., L.M. and H.L.; methodology, H.L., C.C., A.T. and L.M.; software, B.B., A.B., A.T. and H.L.; validation, L.M. and A.B.; formal analysis, A.B., H.L. and A.T.; investigation, B.W., A.B., H.L., L.M. and A.T.; resources, U.R., P.C., C.C. and B.W.; data curation, A.B., B.W., H.L. and C.C.; writing-original draft preparation, A.B., A.T., H.H., J.J.L. and L.M.; writing-review and editing, U.R., P.C., C.C. and B.W.; visualization, A.T.; supervision, U.R. and P.C.; project administration, J.J.L. and L.M.; funding acquisition, B.W., A.T., U.R., P.C., C.C and J.J.L. All authors have read and agreed to the published version of the manuscript.

Funding: This research received no external funding.

Acknowledgments: Anna Trubetskaya, Bernd Wittgens and Anders Brunsvik gratefully acknowledge the financial support from the EU project Biomass Research Infrastructure for Sharing Knowledge (BRISK2). Heiko Lange acknowledges the MIUR Grant 'Dipartimento di Eccellenza 2018-2022' to the Department of Pharmacy of the University of Naples 'Federico II'. Ulrika Rova, Paul Christakopoulos and Leonidas Matsakas would like to thank Bio4Energy, a strategic research environment appointed by the Swedish government, for supporting this work.

Conflicts of Interest: The authors declare no conflict of interest. The funders had no role in the design of the study; in the collection, analyses, or interpretation of data; in the writing of the manuscript, or in the decision to publish the results.

\section{Appendix A. FTIR Analysis}

FTIR spectra of lignin samples are summarized in Table A1.

Table A1. Summary of FT-IR peak/band assignment for fractionated lignin samples. The abbreviations of lignin fractionated from pine sawdust (PL), cotton stalks (CL), sweet sorghum bagasse (SSL), spruce bark with (SBAL) and without acid addition (SBNL) were used.

\begin{tabular}{|c|c|c|}
\hline \multicolumn{2}{|c|}{ Band Position, $\mathrm{cm}^{-1}$} & \multirow[b]{2}{*}{ Peak Assignment } \\
\hline SSL CL & PL SBNL SBAL & \\
\hline \multicolumn{2}{|r|}{2960,2933} & C-H stretch [64] \\
\hline \multicolumn{2}{|r|}{2953} & C-H stretching in $\mathrm{CH}_{2}$ and $\mathrm{CH}_{3}[64]$ \\
\hline 1701 & 1694 & $\mathrm{C}=\mathrm{O}$ stretching, unconjugated [65] \\
\hline \multicolumn{2}{|r|}{1597} & aromatic skeletal vibrations $(S>G)[38]$ \\
\hline \multicolumn{2}{|r|}{1514} & aromatic skeletal vibrations $(G>S)$ [65] \\
\hline 1460 & 1450 & $\mathrm{C}-\mathrm{H}$ deformations in $\mathrm{CH}_{2}$ and $\mathrm{CH}_{3}$ [39] \\
\hline \multirow[t]{2}{*}{1420} & & Aromatic skeletal vibrations [39] \\
\hline & 1372 & C-H bending [66] \\
\hline \multicolumn{2}{|l|}{1328} & S ring breathing [39] \\
\hline 1267 & 1272 & G ring stretching [66] \\
\hline 1215 & 1202 & C-C and C-O stretch [67] \\
\hline \multirow[t]{6}{*}{1163} & 1155 & C-O stretch in ester groups (HGS) [39] \\
\hline & 1115 & C-O stretch, $-\mathrm{OCH}_{3}(\mathrm{~S})[68,69]$ \\
\hline & 1072 & C-O stretching [70] \\
\hline & 1028 & $\mathrm{C}-\mathrm{C}, \mathrm{C}-\mathrm{OH}, \mathrm{C}-\mathrm{H}$ ring [39] \\
\hline & 990 & $\mathrm{HC}=\mathrm{CH}$-out-of-plane deformation [45] \\
\hline & & $\mathrm{CH}$-out-of-plane deformation in ethylenic double bonds [67] \\
\hline 828 & 820 & $\mathrm{CH}$-out-of-plane in positions 2,5 , and 6 of $\mathrm{G}$ units [45] \\
\hline
\end{tabular}




\section{References}

1. Umeki K.; Yamamoto K.; Namioka T.; Yoshikawa K. High temperature steam-only gasification of woody biomass. Appl. Energy 2010, 87, 791-798. [CrossRef]

2. Akin, D.E.; Benner R. Degradation of polysaccharides and lignin by ruminal bacteria and fungi. Appl. Environ. Microbiol. 1988, 54, 1117-1125. [CrossRef] [PubMed]

3. Dutta T.; Papa G.; Wang E.; Sun J.; Isern N.G.; Cort, J.R. Characterization of Lignin Streams during Bionic Liquid-Based Pretreatment from Grass, Hardwood, and Softwood. ACS Sustain. Chem. Eng. 2018, 6, 3079-3090. [CrossRef]

4. Doherty, W.O.S.; Mousavioun, P.; Fellows, C.M. Value-adding to cellulosic ethanol: Lignin polymers. Ind. Crops. Prod. 2011, 33, 259-276. [CrossRef]

5. Alvira P.; Tomas-Pejo E.; Ballesteros M.; Negro M.J. Pretreatment technologies for an efficient bioethanol production process based on enzymatic hydrolysis: A review. Biores. Technol. 2010, 10, 4851-4861. [CrossRef]

6. Trubetskaya, A.; Brown, A.; Tompsett, G.A.; Timko, M.T.; Kling, J.; Umeki, K. Characterization and reactivity of soot from fast pyrolysis of lignocellulosic compounds and monolignols. Appl. Energy 2018, 212, 1489-1500. [CrossRef]

7. Kalogiannis, K.G..; Matsakas, L.; Aspden, J.; Lappas, A.A.; Rova, U.; Christakopoulos, P. Acid Assisted Organosolv Delignification of Beechwood and Pulp Conversion towards High Concentrated Cellulosic Ethanol via High Gravity Enzymatic Hydrolysis and Fermentation. Energies 2018, 23, 1647. [CrossRef]

8. Zhao, X.; Cheng, K.; Liu, D. Organosolv pretreatment of lignocellulosic biomass for enzymatic hydrolysis. Appl. Microbiol. Biotech. 2009, 82, 815-827. [CrossRef] [PubMed]

9. Matsakas, L.; Nitsos, C.; Raghavendran, V.; Yakimenko, O.; Persson, G.; Christakopoulos, P . A novel hybrid organosolv: Steam explosion method for the efficient fractionation and pretreatment of birch biomass. Biotech. Biofuels 2018, 11, 1-14.

10. Zhang, J.; Tang, M.; Viikari, L. Xylans inhibit enzymatic hydrolysis of lignocellulosic materials by cellulases. Biores. Technol. 2012, 121, 8-12. [CrossRef]

11. Kristensen, J.B.; Thygesen, L.G.; Felby, C.; Jorgensen, H.; Elder, T. Cell wall structural changes in wheat straw pretreated for bioethanol production. Biotech. Biofuels 2008, 1, 1-9.

12. Sipponen, M.H.; Rahikainen, J.; Leskinen, T.; Pihlajaniemi, V.; Mattinen, M.L.; Lange, H. Structural changes of lignin in biorefinery pretreatments and consequences to enzyme-lignin interactions. Nordic. Pulp. Paper Res. J. 2018, 32, 550-571. [CrossRef]

13. Kalogiannis, K.G.; Matsakas, L.; Lappas, A.A.; Rova, U.; Christakopoulos, P. Aromatics from Beechwood Organosolv Lignin through Thermal and Catalytic Pyrolysis. Energies 2019, 12, 1606. [CrossRef]

14. Wyman, C.E.; Dale, B.E.; Elander, R.T.; Holtzapple, M.; Ladisch, M.R.; Lee, Y.Y. Coordinated development of leading biomass pretreatment technologies. Biores. Technol. 2005, 96, 1959-1966. [CrossRef] [PubMed]

15. Constant, S.; Wienk, H.L.J.; Frissen, A.E.; de Peinder, P.; Boelens, R.; van Es, D. New insights into the structure and composition of technical lignins: a comparative characterisation study. Green Chem. 2016, 18, 2651-2665. [CrossRef]

16. Nitsos, C.; Rova, U.; Christakopoulos, P. Organosolv Fractionation of Softwood Biomass for Biofuel and Biorefinery Applications. Energies 2018, 11, 1-23.

17. Huber GW.; Iborra S.; Corma A. Synthesis of Transportation Fuels from Biomass: Chemistry, Catalysts, and Engineering. Energies 2006, 106, 4044-4098.

18. Yang, H.; Yan, R.; Chen, H.; Lee, D.H.; Zheng, C. Characteristics of hemicellulose, cellulose and lignin pyrolysis. Fuel 2007, 86, 1781-1788. [CrossRef]

19. Stefanidis, S.D.; Kalogiannis, K.G.; Iliopoulou, E.F.; Michailof, C.M.; Pilavachi, P.A.; Lappas, A.A. A study of lignocellulosic biomass pyrolysis via the pyrolysis of cellulose, hemicellulose and lignin. J. Anal. Appl. Pyrolysis. 2014, 105, 143-150. [CrossRef]

20. Rinaldi, R.; Jastzebski, R.; Clough, M.T.; Ralph, J.; Kennema, M.; Bruijnincx, P.C.A. Paving the Way for Lignin Valorisation: Recent Advances in Bioengineering, Biorefining and Catalysis. Angew. Chem. 2016, 55, 8164-8215. [CrossRef]

21. Karnaouri, A.; Lange, H.; Crestini, C.; Rova, U.; Christakopoulos, P. Chemoenzymatic Fractionation and Characterization of Pretreated Birch Outer Bark. ACS Sustain. Chem. Eng. 2016, 4, 5289-5302. [CrossRef] 
22. Lange, H.; Schiffels, P.; Sette, M.; Sevastyanova, O.; Crestini, C. Fractional Precipitation of Wheat Straw Organosolv Lignin: Macroscopic Properties and structural Insights. ACS Sustain. Chem. Eng. 2016, 4, 5136-5151. [CrossRef]

23. Nitsos, C.; Stoklosa, R.; Lange, H.; Hodge, D.; Rova, U.; Christakopoulos, P. Isolation and Characterization of Organosolv and Alkaline Lignins from Hardwood and Softwood Biomass. ACS Sustain. Chem. Eng. 2016, 4, 5171-5193. [CrossRef]

24. Matsakas, L.; Christakopoulos, P. Fermentation of liquefacted hydrothermally pretreated sweet sorghum bagasse to ethanol at high-solids content. Biores. Technol. 2013, 127, 202-208. [CrossRef]

25. Kemppainen, K.; Siika-aho, M.; Pattathil, S.; Giovando, S.; Kruus, K. Spruce bark as an industrial source of condensed tannins and non-cellulosic sugars. Ind. Crops. Prod. 2014, 52, 158-168. [CrossRef]

26. MS-SEARCH. NIST Mass Spectrometry Data Center: NIST/EPA/NIH Mass Spectral Database. Available online: http:/ / chemdata.nist.gov (accessed on 1 January 2011).

27. Mu, L.; Matsakas, L.; Wu, J.; Chen, M.; Rova, U.; Christakopoulos, P.. Two important factors of selecting lignin as efficient lubricating additives in poly (ethylene glycol): Hydrogen bond and molecular weight. Int. J. Biol. Macromol. 2019, 129, 564-570. [CrossRef] [PubMed]

28. Asikkala, J.; Tamminen, T.; Argyropoulos, D.S. Accurate and Reproducible Determination of Lignin Molar Mass by Acetobromination. J. Agric. Food Chem. 2012, 60, 8968-8973. [CrossRef]

29. Meng, X.; Crestini, C.; Ben, H.; Hao, N.; Pu, Y.; Ragauskas, A.J.. Determination of hydroxyl groups in biorefinery resources via quantitative ${ }^{31}$ P NMR spectroscopy. Nat. Protoc. 2019, 14, 2627-2647. [CrossRef] [PubMed]

30. Gordobil, O.; Moriana, R.; Zhang, L.; Labidi, J.; Sevastyanova, O. Assessment of technical lignins for uses in biofuels and biomaterials: Structure-related properties, proximate analysis and chemical modification. Ind. Crops. Prod. 2014, 83, 155-165. [CrossRef]

31. Guo, H.; Zhang, B.; Qi, Z.; Li, C.; Ji, J.; Dai, T.. Valorization of Lignin to Simple Phenolic Compounds over Tungsten Carbide: Impact of Lignin Structure. ChemSusChem 2016, 10, 523-532. [CrossRef]

32. Nadji, H.; Diouf, P.N.; Benaboura, A.; Bedard, Y.; Riedl, B.; Stevanovic, T. Comparative Study of Lignin Isolated from Alfa grass (Stipa Tenacissima L.). Biores Tech 2009, 100, 3585-3592. [CrossRef]

33. Sluiter, A.; Hames, B.; Ruiz, R.; Scarlata, C.; Sluiter, J.; Templeton, D. Determination of Structural Carbohydrates and Lignin in Biomass. Golden (CO); Report No. NREL/TP-510-42618. Contract No.; DE-AC36-08-GO28308; National Renewable Energy LAboratory: Golden, CO, USA, 2011.

34. Thring, R.W.; Vanderlaan, M.N.; Griffin, S.L. Fractionation of ALCELL lignin by sequential solvent extraction. J. Wood Chem. Technol. 1996, 16, 139-154. [CrossRef]

35. Brodin, I.; Sjöholm, E.; Gellerstedt, G. The behavior of kraft lignin during thermal treatment. J. Anal. Appl. Pyrolysis. 2010, 87, 70-77. [CrossRef]

36. Cui, C.; Sun, R.; Argyropoulos, D.S. Fractional Precipitation of Softwood Kraft Lignin: Isolation of Narrow Fractions Common to a Variety of Lignins. ACS Sustain. Chem. Eng. 2014, 2, 959-968. [CrossRef]

37. Sun, S.L.; Wen, J.L.; Ma, M.G.; Li, M.F.; Sun, R.C. Revealing the Structural Inhomogeneity of Lignans from Sweet Sorghum Stem by Successive Alkali Extractions. J. Agric. Food Chem. 2013, 61, 4226-4235. [CrossRef]

38. El-Hendawy, A.N.A. Variation in the FTIR spectra of a biomass under impregnation, carbonization and oxidation conditions. J. Anal. Appl. Pyrolysis. 2004, 75, 159-166. [CrossRef]

39. Inkrod, C.; Raita, M.; Champreda, V.; Laosiripojana, N. Characteristics of Lignin Extracted from Different Lignocellulosic Materials via Organosolv Fractionation. BioEnergy Res. 2018, 11, 277-290. [CrossRef]

40. Abdelaziz, O.Y.; Brink, D.P.; Prothmann, J.; Ravi, K.; Sun, M.; Garcia-Didalgo, J. Biological valorization of low molecular weight lignin. Biotechnol. Adv. 2016, 34, 1318-1346. [CrossRef]

41. Pawliszyn, J. Theory of Solid-Phase Microextraction. J. Chromatogr. Sci. 2000, 38, 270-278. [CrossRef] [PubMed]

42. Rocha, S.M.; Gonçalves, V.; Evtuguin, D.; Delgadillo, I. Distinction and identification of lignins based on their volatile headspace composition. Talanta 2008, 75, 594-597. [CrossRef]

43. Tarasov, D.; Leitch, M.; Fatehi, P. Lignin-carbohydrate complexes: Properties, applications, analyses, and methods of extraction: A review. Biotechnol. Biofuels 2018, 11, 1-28.

44. Koller, J.; Baumer, U.; Kaup, Y.; Schmid, M.; Weser, U. Analysis of a pharaonic embalming tar. Nature 2003, 425, 784. [CrossRef] [PubMed] 
45. Faix, O. Classification of Lignins from Different Botanical Origins by FT-IR Spectroscopy. Holzforschung 1991, 45, 21-28. [CrossRef]

46. Xue, L.; Zhao, Z.; Zhang, Y.; Chu, D.; Mu, J. Analysis of Gas Chromatography-Mass Spectrometry Coupled with Dynamic Headspace Sampling on Volatile Organic Compounds of Heat-Treated at High Temperatures. Biores 2016, 11, 3550-3560. [CrossRef]

47. Oliveira, D.; Finger-Teixeira, A.; Mota, T.; Salvador, V.H.; Moreira-Vilar, F.C.; Molinari, H.B.C. Ferilic Acid: A Key Component in Grass Lignocellulose Recalcitrance to Hydrolysis. Plant Biotechnol. J. 2015, 13, 1224-1232. [CrossRef]

48. Gutierrez, A.; Rodriguez, I.M.; Del Rio, J.C. Chemical Characterization of Lignin and Lipid Fractions in Industrial Hemp Bast Fibbers Used for Manufacturing High-Quality Paper Pulps. J. Agric. Food Chem. 2006, 54, 2138-2144. [CrossRef]

49. Marques, G.; Gutierrez, A.; del Rio, J.C. Chemical Characterization of Lignin and Lipid Fractions in Leaf Fibers of Curaua (Ananas erectifolius). J. Agric. Food Chem. 2007, 55, 1327-1336. [CrossRef]

50. Surup, G.R.; Foppe, M.; Schubert, D.; Deike, R.; Heidelmann, M.; Trubetskaya, A. The effect of feedstock origin and temperature on the structure and reactivity of char from pyrolysis at $1300-2800{ }^{\circ} \mathrm{C}$. Fuel 2019, 235, 306-316. [CrossRef]

51. Surup, G.R.; Nielsen, H.K.; Heidelmann, M.; Trubetskaya, A. Characterization and reactivity of charcoal from high temperature pyrolysis $\left(800-1600^{\circ} \mathrm{C}\right)$. Fuel 2019, 235, 1544-1554. [CrossRef]

52. Du, S.; Valla, J.A.; Bollas, G.M. Characteristics and origin of char and coke from fast and slow, catalytic and thermal pyrolysis of biomass and relevant model compounds. Green Chem. 2013, 15, 3214-3229. [CrossRef]

53. Cen, K.; Cao, X.; Chen, D.; Zhou, J.; Chen, F.; Li, M. Leaching of alkali and alkaline earth metallic species (AAEMs) with phenolic substances in bio-oil and its effect on pyrolysis characteristics of moso bamboo. Fuel Process. Technol. 2020, 200, 106332. [CrossRef]

54. Yan, K.; Liu, F.; Chen, Q.; Ke, M.; Huang, X.; Hu, W. Pyrolysis characteristics and kientics of lignin derived from enzymatic hydrolysis residue of bamboo pretreated with white-rot fungus. Biotechnol. Biofuels 2016, 9,1-11.

55. Cherif, M.F.; Trache, D.; Brosse, N.; Benaliouche, F.; Tarchoun, A.F. Comparison of the Physicochemical Properties and Thermal Stability of Organosolv and Kraft Lignins from Hardwood and Softwood Biomass for Their Potential Valorization. Waste Biomass Valoriz 2020, 15, 1-13.

56. Shimizu, S.; Yokoyama, T.; Akiyama, T.; Matsumoto, Y. Reactivity of Lignin with Different Composition of Aromatic Syringyl/Guaiacyl Structures and Erythro/Threo Side Chain Structures in $\beta-O-4$ Type during Alkaline Delignification: As a Basis for the Different Degradability of Hardwood and Softwood Lignin. J. Agric. Food Chem. 2012, 60, 6471-6476. [CrossRef] [PubMed]

57. Trubetskaya, A.; Jensen, P.A.; Jensen, A.D.; Umeki, K.; Gardini, D.; Kling, J.; Glarborg, P. Effects of several types of biomass fuels on the yield, nanostructure and reactivity of soot from fast pyrolysis at high temperatures. Appl. Energy 2016, 171, 468-482. [CrossRef]

58. Jiang, G.; Nowakowski, D.J.; Bridgwater, A.V. Effect of the temperature on the composition of lignin pyrolysis products. Energy Fuel 2010, 24, 4470-4475. [CrossRef]

59. Trubetskaya, A.; Larsen Andersen, M.; Talbro Barsberg, S. The Nature of Stable Char Radicals: An ESR and DFT Study of Structural and Hydrogen Bonding Requirements. ChemPlusChem 2018, 83, 780-786. [CrossRef] [PubMed]

60. Mood, S.H.; Golfeshan, A.H.; Tabatabaei, M.; Abbasalizadeh, S.; Ardjmand, M. Comparison of different ionic liquids pretretment for barley straw enzymatic saccharification. Biotech 2013, 3, 399-406.

61. Kumar, A.; Kumar, J.; Bhaskar, T. Utilization of lignin: A sustainable and eco-friendly approach. J. Energy Inst. 2020, 93, 235-271. [CrossRef]

62. Brauns, F.E.; Brauns, D.A. The Thermal Decomposition of Lignin. In The Chemistry of Lignin; Academic Press: Cambridge, MA, USA, 1960; p. 814.

63. Fengel, D.; Wegener, G. Wood: Chemistry, Ultrastructure, Reactions; Walter de Gruyter: Berlin, Germany, 1989; p. 612.

64. Arellano, O.; Flores, M.; Guerra, J.; Hidalgo, A.; Rojas, D.; Strubinger, A. Hydrothermal Carbonization of Corncob and Characterization of the Obtained Hydrochar. Chem. Eng. Trans. 2016, 50, 235-240. 
65. Adapa, P.K.; Tabil, L.G.; Schoenau, G.J.; Canam, T.; Dumonceaux, T. Quantitative Analysis of Lignocellulosic Components of Non-Treated and Steam Exploded Barley, Canola, Oat and Wheat Straw Using Fourier Transform Infrared Spectroscopy. J. Agric. Sci. Technol. B 2011, 1, 177-188.

66. Fan, M.; Dai, D.; Huang, B. Chapter 3 Fourier Transform Infrared Spectroscopy for Natural Fibres. In Fourier Transform. IntechOpen 2012, 3, 45-68.

67. Lisperguer, J.; Perez, P.; Upizar, S. Structure and thermal properties of lignins: characterization by infrared spectroscopy and differential scanning calorimetry. J. Chil. Chem. Soc. 2009, 54, 460-463. [CrossRef]

68. Arafat, A.; Samad, S.A.; Masum, S.M.; Moniruzzaman, M. Preparation and Characterization of Chitosan from Shrimp shell waste. IJSER 2015, 6, 538-541.

69. Liu, Z.; Quek, A.; Hoekman, S.K.; Balasubramanian, R. Production of solid biochar fuel from waste biomass by hydrothermal carbonization. Fuel 2013, 103, 943-949. [CrossRef]

70. Lopes, J.O.; Garcia, R.A.; Souza, N.D. Infrared spectroscopy of the surface of thermally-modified teak juvenile wood. Maderas Cienc. Technol. 2018, 20, 737-746. [CrossRef]

(C) 2020 by the authors. Licensee MDPI, Basel, Switzerland. This article is an open access article distributed under the terms and conditions of the Creative Commons Attribution (CC BY) license (http://creativecommons.org/licenses/by/4.0/). 